\title{
Performance Analysis of Boost Converter for Constant Voltage Applications Under the Variation of Closed-Loop PI Controller Parameters
}

\author{
Shetu Roy, Sumaiya Umme Hani, Mohammad Abdul Mannan
}

\begin{abstract}
PI Controller is one of the eminent controller which holds majority of the applications in industrial purposes. This paper encompasses an analysis on the performance of PI controller for DC-DC Boost converter for constant voltage application where codifications of gains of PI controller are done in terms of natural frequency and damping factor. The converter has been designed to operate in continuous conduction mode and the voltage mode control strategy has been proposed by using pulse width modulation (PWM) with the PI controller. A set of gain parameters of PI controller can be selected to obtain the output of the PI controller with low rise time, quick settling time and also with more stability features. The effectiveness of this boost (or step up) converter with different set of PI controller gains has been verified through simulation where MATLAB/Simpower is used as the utensil. All the simulation results intrinsically emphasized on efficient performance of the proposed control strategy.
\end{abstract}

Keywords-Boost Converter; Duty Cycle; PI Controller; PWM Generator $(D C-D C)$;

\section{INTRODUCTION}

The purpose of power electronics is to convert electrical energy from one form to another, which again ensures that the electrical energy must reach the load with highest efficiency. The concrete notion of power electronics is to decrease the size of the devices to attain cost effectiveness, spatial effectiveness and also to secure efficient operation. Four types of converters are realized in power electronics: AC-DC converter, AC-AC converter, DC-AC converter and DC-DC converter [1]. DCDC converter can be designed to decrease [2] or increasing [3] or both decrease and increase $[4,5]$ of output voltage level.

For different applications such as battery-operated systems,

\section{Shetu Roy}

Graduate Student, MEEE

American International University-Bangladesh (AIUB).

Dhaka, Bangladesh

email: sheturoy33@gmail.com

Sumaiya Umme Hani

Lecturer. Dept of EEE

American International University-Bangladesh (AIUB).

Dhaka, Bangladesh

email: sumaiya@aiub.edu solar cell operated system the voltage level is needed to be increased and hence boost converters are often realized such as in electrical power system, communication, electronic devices etc. [6]. Sometimes boost converters are supplied with AC power signal in which the AC power signal is first converted into unregulated DC and hereafter the unregulated DC is converted into regulated DC signal. Such boost converters are called AC to DC converter. It is to be noted that for a regulated converter the output voltage must be maintained constant with the variation of input voltage and this in turn causes the need of a controller to sustain a fixed output. This research work introduces the design of boost converter connected with PI controller to sustain a constant output voltage with the variation of closed-loop PI controller parameters [6].

A proportional integral (PI) controller [7] is a control loop feedback mechanism widely used in industrial control, electronics \& different technological systems for its simple, accurate and robust operating mechanism. With its effective controlling mechanism, the PI controller delivers a constant output by comparing an input signal with a set of defined values. The two governing parameters of PI controller: the proportional and the integral $[2,7]$ are mainly varied through different effective methods [8] in order to achieve the desired fixed output signal. In this modern era, multiple impressive, firm and robust controlling mechanisms are realized to codify the aforementioned parameters of PI controller to attain the appropriate and fixed output. Over and above, DC-DC converters now-a-days are also incorporated with PI controller to get improved and precise output.

The performance of PI controller based systems is mainly realized through observing few criterions such as overshoot, peak time and settling time. Earlier, the performance of PI controller incorporated with Buck converter [2] had been done where a set of parameters of PI controller was codified and finalized using trial and error method to conform the desired output. Additionally, using Ziegler-Nichols method the PI controller parameters were varied to attain the desired outcome [3].

This paper emphasizes on the design of Boost converter operated in closed loop system with PI controller to acquire the perpetual output signal for various applications such as grid connected inverter systems, wave energy conversion systems, solar systems etc. In the proposed system, as the input is kept constant, thus the desired consistent output is obtained by

\section{Mohammad Abdul Mannan}

Associate Professor and Head (UG Program), Dept. of EEE

American International University-Bangladesh (AIUB).

Dhaka, Bangladesh

email: mdmannan@aiub.edu 
regulating the closed loop parameters. To be precise, the regulation of the closed loop PI controller parameters is done implying pole placement technique and the output of the boost converter is monitored. The performance of the suggested system is verified using MATLAB/Simpower environment and it can be concluded that the simulation results do satisfy the expected outcome which in turn ensure that the proposed system can be utilized for its reliable, commendable, robust and firm performance.

\section{Circuit Diagram and Operation of a DC-DC Boost CONVERTER}

Fig. 1 [1] shows the basic circuit diagram of boost dc-dc converter where the input voltage is being raised at the output side. This converter can be designed using power semiconductor switching devices and discrete electrical and electronics components.

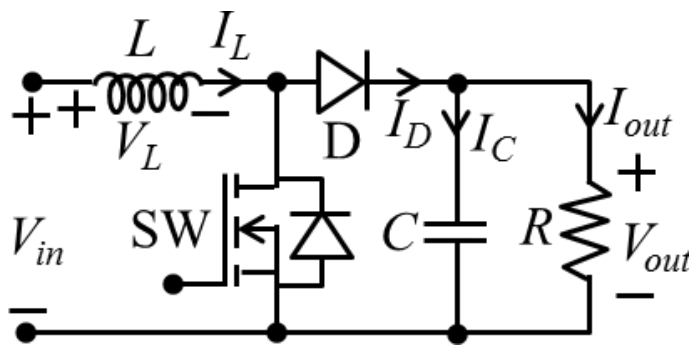

Fig. 1. Basic circuit of boost dc-dc converter.

Boost converter operates at both Continuous \& discontinuous conduction mode. In the continuous conduction mode, the boost converter circuit switch is controlled using a pulse width modulator (PWM).

Depending on the switching mechanism the operation of boost converter is divided into two modes.

\section{A. Mode 1 (Switch is Closed)}

Mode 1 begins when the switch SW is turned on at $\mathrm{t}=0$ as shown in Fig. 2. In this mode, energy will be developed in the inductor $\mathrm{L}$ and the load power is received from capacitor $\mathrm{C}$.

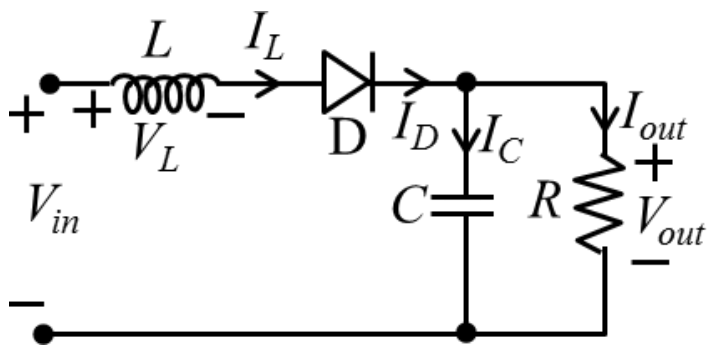

Fig. 2. Boost converter circuit diagram for mode 1.

The voltage and current relation for mode 1 are given by Eqs. (1) and (2):

$$
\begin{aligned}
& I_{C}=-I_{\text {out }} \\
& V_{\text {in }}=L \frac{d I_{L}}{d t}
\end{aligned}
$$

\section{B. Mode 2 (Switch is Open)}

During this mode, the switch SW is maintained closed that is, it is in open circuit condition and no current will flow through the switch, instead the current would now flow through inductor $\mathrm{L}$, diode $\mathrm{D}$, output capacitor $\mathrm{C}$, and load $\mathrm{R}$ as shown in Fig. 3.

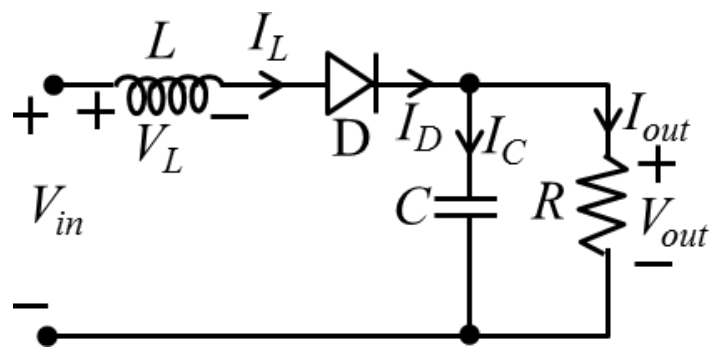

Fig. 3. Boost converter circuit diagram for mode 2.

During this mode the stored energy in $\mathrm{L}$ is delivered to the capacitor $\mathrm{C}$ and the load $\mathrm{R}$. The voltage and current relation for mode 2 are given by Eqs. (3) and (4):

$$
\begin{aligned}
& I_{L}=I_{C}+I_{\text {out }} \\
& V_{\text {in }}=L \frac{d I_{L}}{d t}+V_{C}
\end{aligned}
$$

\section{Calculation of Designed Converter Parameters}

To obtain the desired output voltage and load current with the restricted ripple, the converter must be facilitated with inductor and capacitor whose value can be obtained by the following Eqs. (5) and (6).

$$
\begin{aligned}
& L=\frac{V_{\text {in }}\left(V_{\text {out }}-V_{\text {in }}\right)}{\Delta I_{L} f_{s} V_{\text {out }}} \\
& C=\frac{D I_{\text {out }}}{f_{s} \Delta V_{\text {out }}}
\end{aligned}
$$

where, $V_{\text {out }}=V_{\text {in }} /(1-D), f_{\mathrm{S}}=$ Switching frequency, $\Delta \mathrm{IL}=$ Peak to peak ripple current, $\Delta V_{\text {out }}=$ Peak to peak ripple voltage, $D=$ Duty cycle.

Taking input voltage $\left(V_{i n}\right)=96.18$ volts, output voltage $\left(V_{\text {out }}\right)=400$ volts, output current $\left(I_{\text {out }}\right)=33 \mathrm{~A}$, Duty cycle $(D)=$ $75.95 \%$, Switching frequency $\left(f_{S}\right)=33.4 \mathrm{KHz}, \Delta V_{\text {out }}=15 \mathrm{~V}, \Delta I_{L}$ $=40.17 \mathrm{~mA}$, the value of inductor and capacitor are obtained as: $L=54.49 \mathrm{mH}, C=0.00005 \mathrm{~F}$. 


\section{DESIGN OF PI CONTROLler}

As mentioned above, the governing parameters of PI controller: proportional gain $(\mathrm{KP})$ and integral gain $(\mathrm{KI})$ are the main factors that are been codified to get the desired output. Variation in these parameters with different methods are called PI tuning. The expression of PI controller for a boost converter can be given by Eq. (7):

$$
v_{\text {com }}(t)=K_{P} e(t)+K_{I} \int e(t) d t
$$

where, $v_{\text {com }}(\mathrm{t})=$ controller output signal, $e(t)=$ voltage controller error, $K_{P}=$ proportional gain, $K_{I}=$ integral gain.

Regulation of parameters means step by step codification of the parameters up till the expected outcome is achieved. This again subsides the error between the variable signal and the defined set values [8]. Various methods for regulating the parameters are in practice. However, this research work focused on the pole placement technique in the transfer function of boost converter to vary the parameters.

\section{Transfer FunCtion OF Closed LoOP BoOST CONVERTER SYSTEM}

In this Fig. 4, Vout is given to the pulse width modulator. The output of the PWM is compared with Vref which is again supplied to the PI controller. Finally, the output from the PI controller is added with Vin which is given to the system [3].

From Fig. 4, the error voltage, compensating voltage, and output voltage are given by Eqs. (8), (9) and (10):

$$
\begin{aligned}
E(s) & =V_{\text {ref }}-d V_{\text {out }} \\
V_{\text {com }} & =\left[K_{P}+\left(K_{I} / s\right)\right] E(s)
\end{aligned}
$$

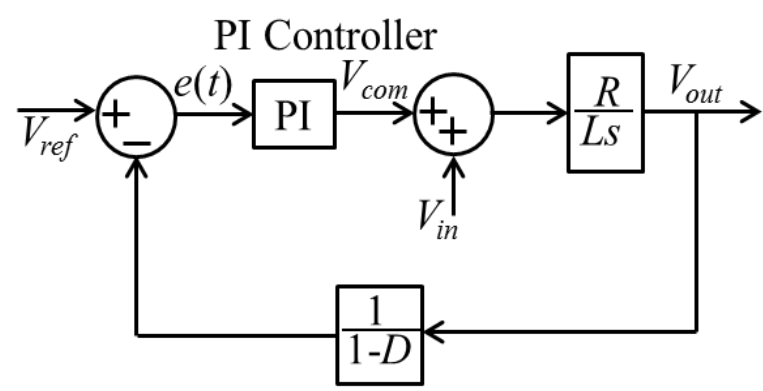

Fig. 4. Closed loop system of boost converter [3].

$$
V_{\text {out }}=(R / L s)\left[V_{c o m}+V_{\text {in }}\right]
$$

where, $d=\frac{1}{1-D}$;

Combining Eqs. (8) to (10) with the consideration that reference voltage is a step function (i.e. Vref $=0$ ), the closedloop transfer function can be obtained as follows:

$$
\frac{V_{\text {out }}(s)}{V_{\text {ref }}(s)}=\frac{(R / L) s}{s^{2}+2 \zeta \omega_{n} s+\omega_{n}^{2}}
$$

where, $\omega_{n}=\sqrt{\frac{R d K_{I}}{L}}$ and $2 \zeta \omega_{n}=\frac{R d K_{P}}{L}$

According to the pole-placement technique of closed-loop transfer function of Eq. (11), the gain of PI controller in terms of natural frequency $\left(\omega_{\mathrm{n}}\right)$ and damping factor $(\zeta)$ can be obtained as:

$$
\begin{gathered}
K_{P}=\frac{2 \zeta \omega_{n} L}{R d} \\
K_{I}=\frac{L \omega_{n}^{2}}{R d}
\end{gathered}
$$

PI controller parameters can be tuned by using Eqs. (120 and (13) for closed-loop system with boost converter as shown in Fig. 4. Here, undamped natural frequency, $\omega_{\mathrm{n}}$ and damping ratio or factor, $\zeta$ has been used to tune the controller parameters, $K_{P} \& K_{I}$

The undamped natural frequency, $\omega n$ determines how fast the system oscillates during any transient response. The higher the natural frequency, the lower the system oscillates. The damping factor, $\zeta$ determines how much the system oscillates as the response decays toward steady state. The damping factor is a parameter that characterizes the frequency response of the output voltages. It is an influence within an oscillatory system that has the effect of reducing, restricting or preventing its oscillations. The higher the damping ratio $(\zeta)$, the lower the oscillation of the system [7].

Different performance evaluating terms overshoot (Mp), peak time (Tp), and settling time (Ts) can be given by:

$$
\begin{aligned}
& M_{p}=e^{\left(-\pi \zeta / \sqrt{1-\zeta^{2}}\right)} \\
& T_{p}=\pi /\left(\omega_{n} \sqrt{1-\zeta^{2}}\right) \\
& T_{s}=\frac{4}{\zeta \omega_{n}}
\end{aligned}
$$

The overshoot, peak time and settling time are calculated for different values of natural frequency $\left(\omega_{n}\right)$ and damping factor $(\zeta)$ to evaluate the performance of PI controller.

\section{DESIGN OF CLOSED-LOOP BOOST CONVERTER WITH PI CONTROLLER IN MATLAB/SIMPOWER SYSTEM}

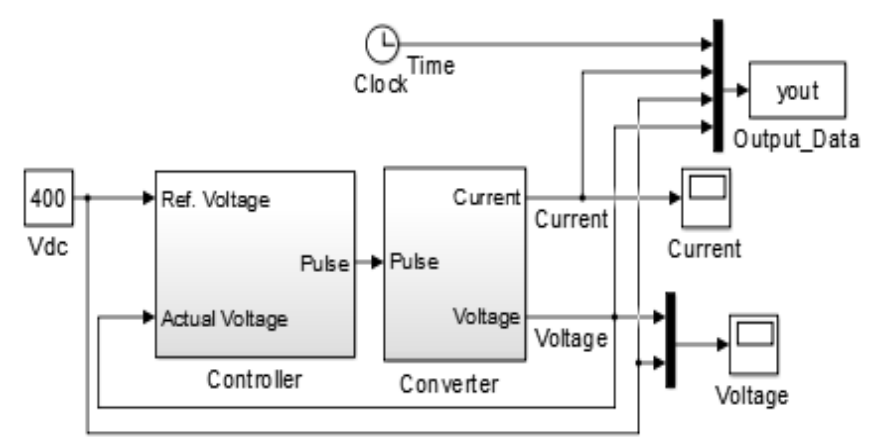

Fig. 5. Simpower model of closed loop system. 
The proposed closed loop system incorporated with boost converter has been developed in MATLAB/Simpower System in order to assess its performance. The entire designed model of the converter with PI controller is built in MATLAB/Simpower utensil and the demonstration is shown in Fig. 5.

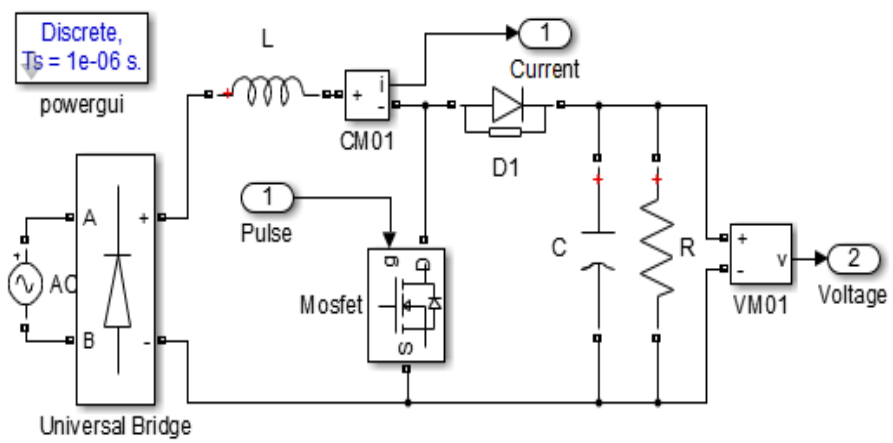

Fig. 6. Boost converter in closed loop system.

The internal structure of converter (including rectifier and DC-DC chopper) of Fig. 5 is shown in Fig. 6 and the interior of the controller block of Fig. 5 is shown in Fig. 7.

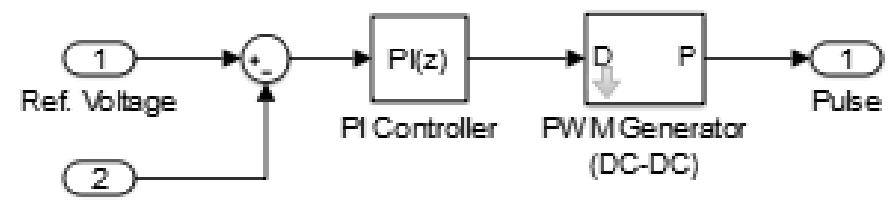

Actual Voltage

Fig. 7. PI controller for closed loop system.

The ac supply voltage is converted to unregulated dc voltage by using bridge converter as shown in Fig. 6 . Then unregulated $\mathrm{dc}$ voltage is augmented by using the boost converter. To boost-up the voltage the desired duty cycle is attained from the PI controller. Based on the desired duty cycle the MOSFET is turned-on (operate in mode 1 as shown in Fig. 2) and turned-off (operate in mode 2 as shown in Fig. 3).

\section{SIMULATION RESULTS}

The variation in parameters for over-damped phenomena is been commenced with taking median values into account for the gain parameters $\left(K_{P} \& K_{I}\right)$ and then gradually the parameters are varied with $\omega_{n}$ and $\zeta$ up till adequate damping ratio is been acquired. Once a proper damping ratio is obtained, the gain parameters are again adjusted until the instability \& desired performance are achieved. Here, $\omega n$ has been set at 8 and damping factor $\zeta$ has been selected to be 0.2 . $K_{P}$ and $K_{I}$ both are changed with $\omega_{n}$. The value of $\omega_{n}$ is stable within a specified range. The voltage waveform shows constant responses when the value is set at 18 . However, when the regulation exceeds the value 18 , the system starts to oscillate and it continues till 20 and beyond 20 entire system gives unstable response.

With the change of $\zeta$, Only $K_{P}$ is changed, $K_{I}$ remains constant. $K_{P}$ increases with the increase in $\zeta$. With this increasing $K_{P}$, the system overshoot will be low. Withal it is been observed that if the value of $\zeta$ is increased beyond 0.6 , the system will be again unstable.
In the Fig. 8, the blue line indicates the reference voltage and the red line indicates the actual voltage. Then $K_{P}$ is 0.0002 and $K_{I}$ is 0.0060 . The overshoot obtained is 0.52 , peak time is $0.4010 \mathrm{~s}$ and settling time is $1.875 \mathrm{~s}$. In the Fig. 9, the blue line indicates the actual current response.

\section{A. Simulation Result with Variation of Natural Frequency}

In Figs. 8 and 9, the blue fine line depicts the reference voltages and the red lines delineate the actual voltages. The simulation results for different values of natural frequency are shown in Fig. 10 to Fig. 14. From the aforementioned figures, it is found that when the values of $\omega_{n}$ increases gradually, the gain parameters $K_{P} \& K_{I}$ also increases, which in turn shows reduction in peak time \& settling time decreases. This finally ensures a fixed output voltage even though the overshoots in the output remain unchanged [4].

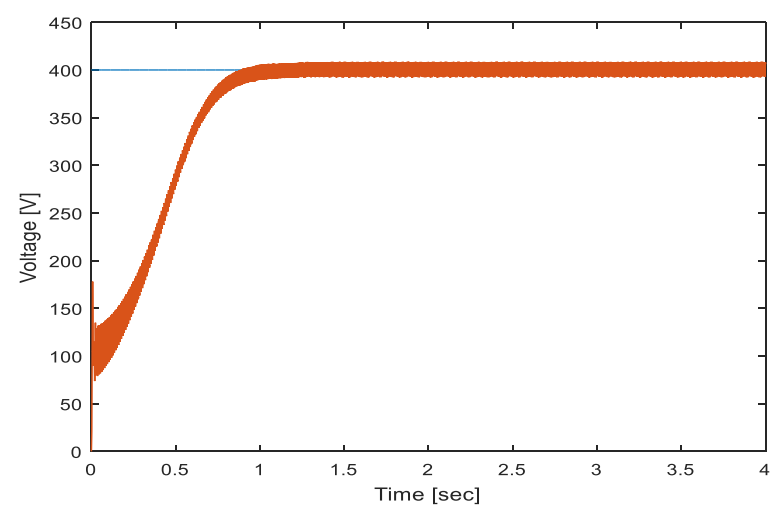

Fig. 8. Closed loop voltage response for $\omega_{n}=8 \mathrm{rad} / \mathrm{s}$ and $\zeta=0.2$.

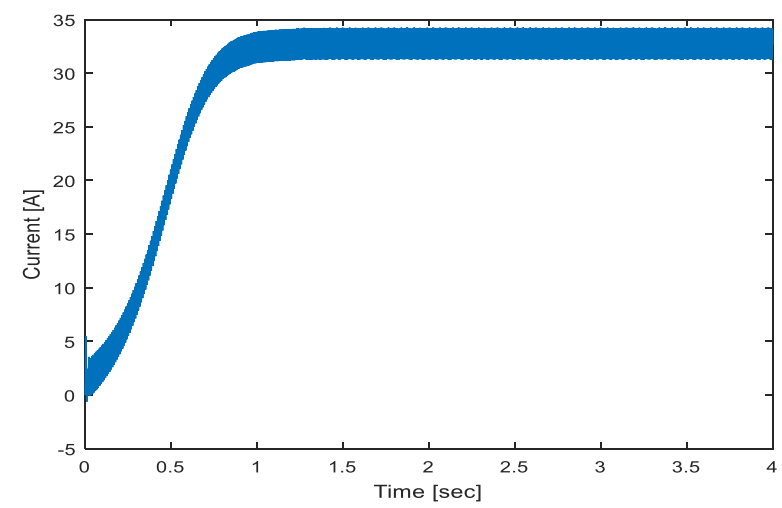

Fig. 9. Closed loop current response for $\omega_{n}=8$ and $\zeta=0.2$.

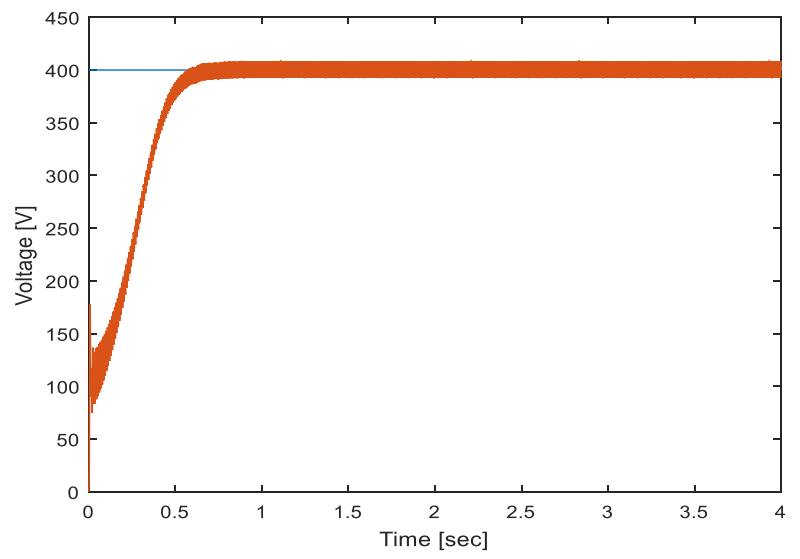

Fig. 10. Output voltage vs time when $\omega_{n}=10 \mathrm{rad} / \mathrm{s}$. 


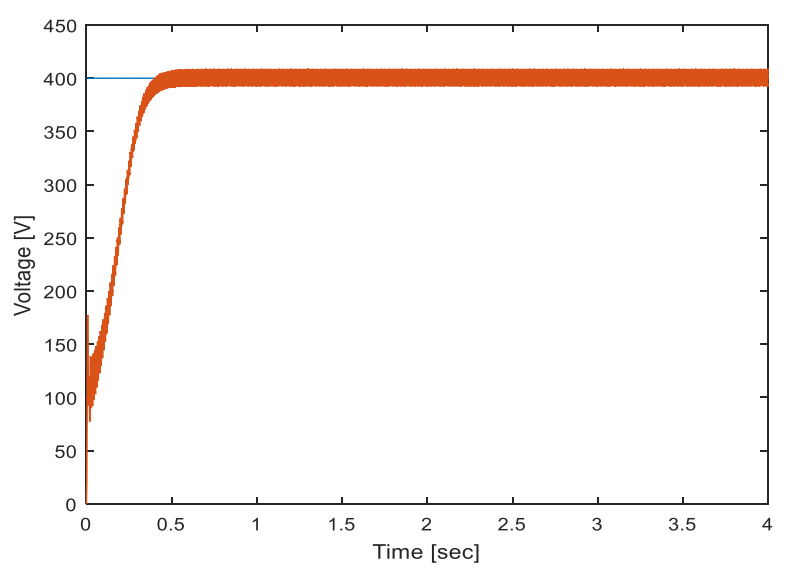

Fig. 11. Output voltage vs time when $\omega_{n}=12 \mathrm{rad} / \mathrm{s}$.

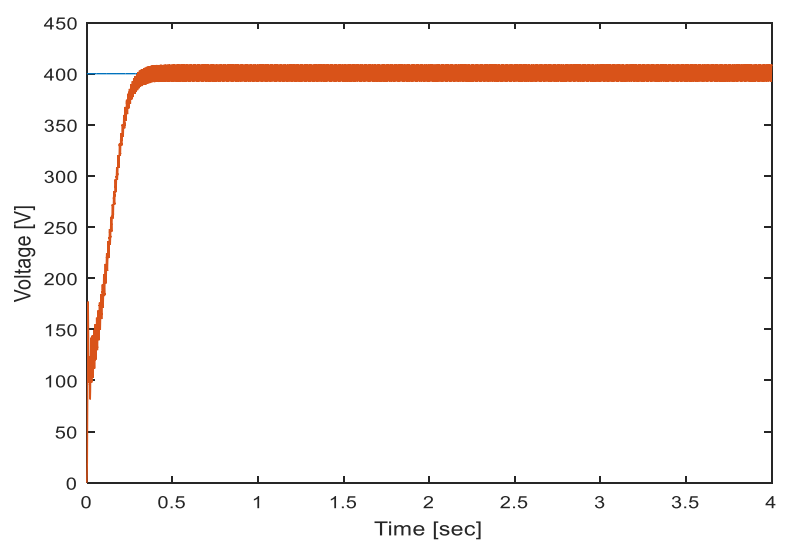

Fig. 12. Output voltage vs time when $\omega_{n}=14 \mathrm{rad} / \mathrm{s}$.

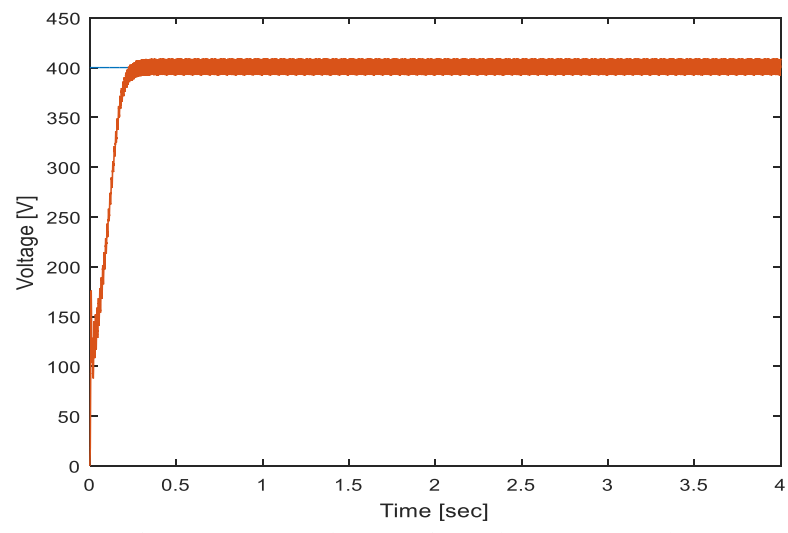

Fig. 13. Output voltage vs time when $\omega_{n}=16 \mathrm{rad} / \mathrm{s}$.

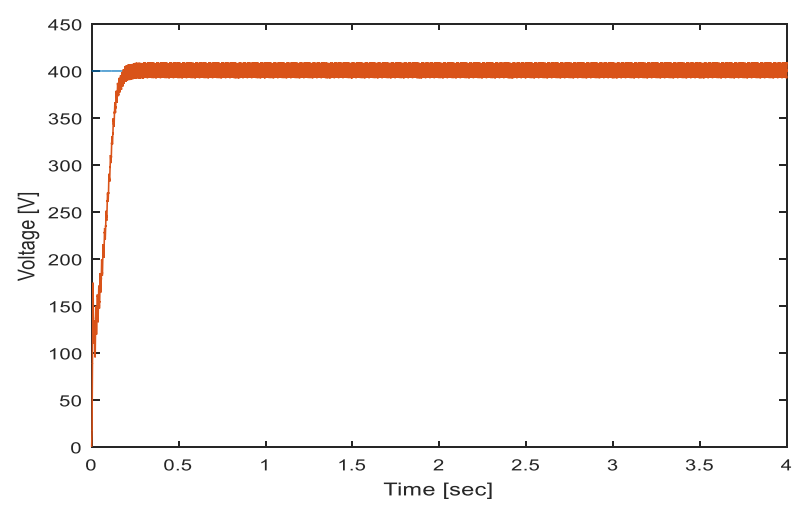

Fig. 14. Output voltage vs time when $\omega_{n}=18 \mathrm{rad} / \mathrm{s}$.
For values beyond $18 \mathrm{rad} / \mathrm{s}$, for instance with $19 \mathrm{rad} / \mathrm{s} \& 20$ $\mathrm{rad} / \mathrm{s}$, the system response will oscillate and the steady state error will increase. If the value is further boosted, then the system will be unstable. Augmentation of $K_{I}$ removes steady state error, but that again should be done with in the restriction as large value of $K_{I}$ will give rise to instability. $K_{I}$ will increase with the increase in $K_{P}$ with respect to $\omega_{n}$. The voltage responses will remain constant until the value of $\omega_{n}$ stays with in range of $20 \mathrm{rad} / \mathrm{s}$.

The voltage responses shown above describes almost constant values for variation of $\omega_{n}$. But there are some difference in overshoots, peak times and settling times [10, 11]. Table 1 shows the distinctiveness of different values as per their positions.

If $\omega_{n}$ is increased, then $K_{P}$ an $K_{I}$ is increased. The more the $\mathrm{KP}$ and KI increases, the more the steady state error will be decreased.

Different performance parameters of responses for the variation of natural frequency has been summarized in Table 1.

TABLE I. VARIATION OF OVERSHOOT, PEAK TIME AND SETTLING TIME DUE TO THE VARIATION OF NATURAL FREQUENCY

\begin{tabular}{|c|c|c|c|c|c|}
\hline \multirow{2}{*}{$\begin{array}{c}\omega_{\mathrm{n}} \\
(\mathrm{rad} / \mathrm{s})\end{array}$} & \multirow[b]{2}{*}{$\mathbf{K}_{\mathbf{P}}$} & \multirow[b]{2}{*}{$\mathbf{K}_{\mathbf{I}}$} & \multicolumn{3}{|c|}{ Voltage $\left(V_{\text {out }}\right)$} \\
\hline & & & $\mathbf{M}_{\mathbf{P}}(\mathbf{V})$ & $\begin{array}{l}\mathbf{T}_{\mathbf{P}} \\
(\mathbf{s})\end{array}$ & $\begin{array}{l}\mathbf{T}_{\mathbf{S}} \\
(\mathbf{s})\end{array}$ \\
\hline 8 & 0.0002 & 0.006 & 0.52 & 0.401 & 1.875 \\
\hline $\begin{array}{c}10 \\
\text { (Fig.10) } \\
\end{array}$ & 0.0003 & 0.009 & 0.52 & 0.320 & 1.5 \\
\hline $\begin{array}{c}12 \\
\text { (Fig.11) }\end{array}$ & 0.0004 & 0.013 & 0.52 & 0.267 & 1.25 \\
\hline $\begin{array}{c}14 \\
\text { (Fig.12) }\end{array}$ & 0.0005 & 0.018 & 0.52 & 0.229 & 1.071 \\
\hline $\begin{array}{c}16 \\
\text { (Fig.13) } \\
\end{array}$ & 0.0005 & 0.024 & 0.52 & 0.200 & 0.937 \\
\hline $\begin{array}{c}18 \\
\text { (Fig.14) }\end{array}$ & 0.0006 & 0.030 & 0.52 & 0.178 & 0.83 \\
\hline
\end{tabular}

\section{B. Simulation Result with Variation of Damping Factor}

The simulation results for different values of natural frequency are shown Fig. 15 to Fig. 20. For these Figs. 15, 16, $17,18,19$ and 20 it is found that when the values of $\zeta$ increases in regular manner, then $K_{P}$ increases, overshoot \& settling time decreases and peak time increases. And finally this establishes constant output voltage [8].

If the value of $\zeta$ is further increased, then the system response will be unstable. The overshoot will be too less with the increased value of $\zeta$. With in the range of 0.1 to 0.6 , the output voltage responses will remain constant.

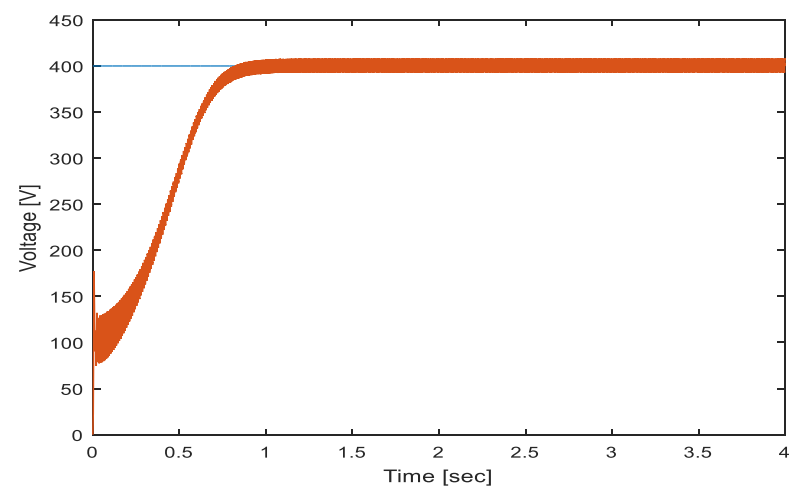

Fig. 15. Output voltage vs time when $\zeta=0.1$. 
Overshoot is important and closely related to damping ratio. It does not depend on undamped natural frequency. When the damping ratio reaches somewhere around 0.7, then the overshoot diminishes and the system becomes unstable.

The voltage responses shown above exhibits constant values for variation of $\zeta$ with some deviations in overshoots, different peak times and different settling times [11]. The different positions of different values are showed in Table 2. The values of Table 2 are obtained by using the formulas of Eqs. (14) to (16).

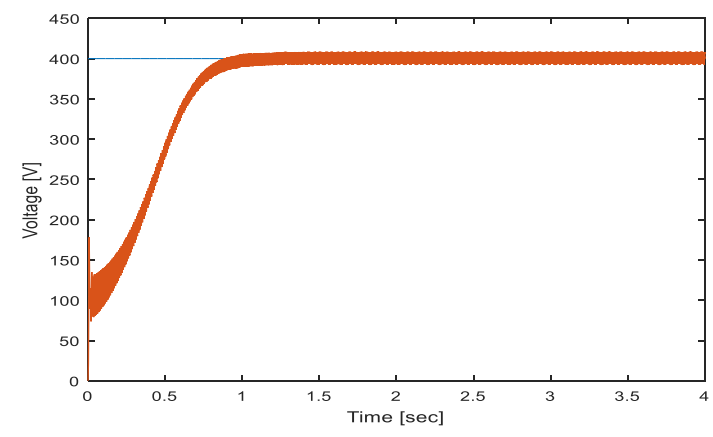

Fig. 16. Output voltage vs time when $\zeta=0.2$.

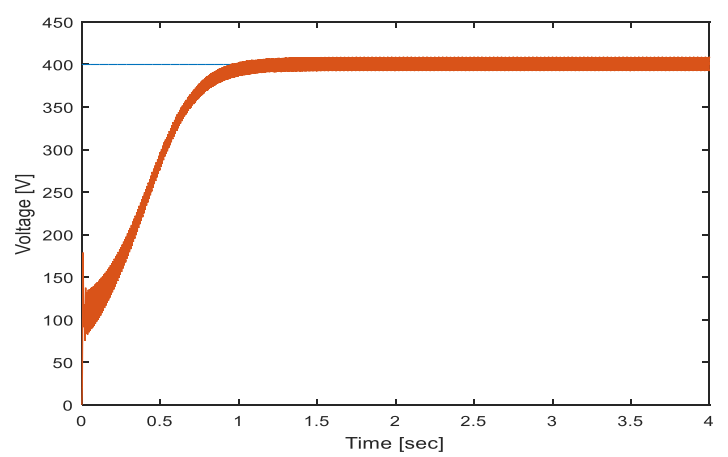

Fig. 17. Output voltage vs time when $\zeta=0.3$.

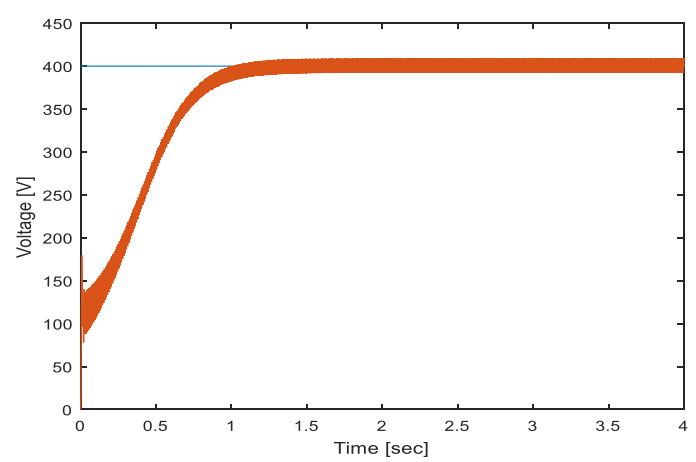

Fig. 18. Output voltage vs time when $\zeta=0.4$.

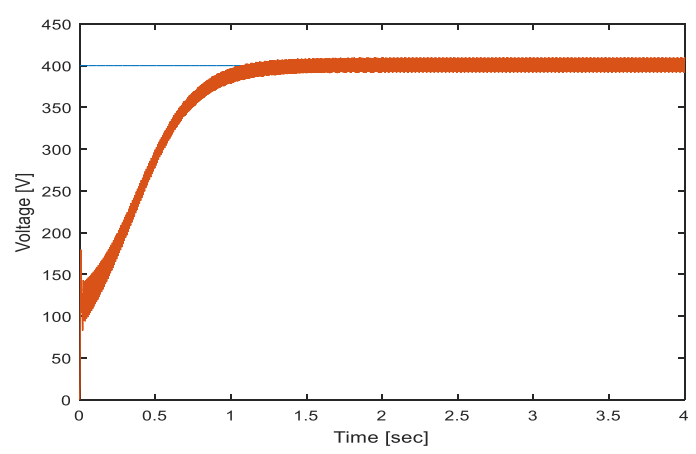

Fig. 19. Output voltage vs time when $\zeta=0.5$.

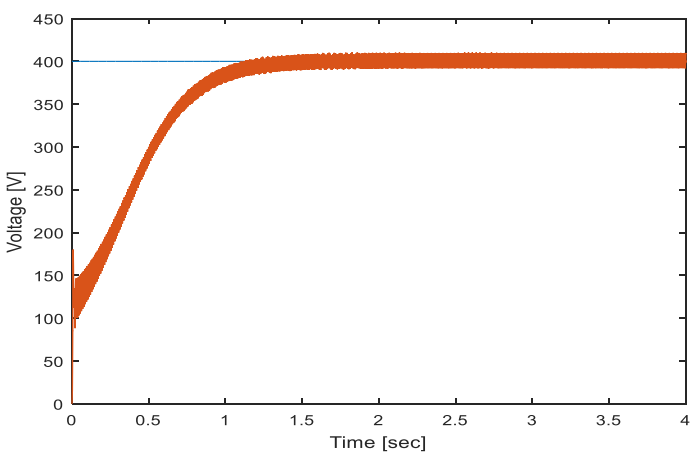

Fig. 20. Output voltage vs time when $\zeta=0.6$.

\section{VIII.CONCLUSION}

In this paper, the transfer function of boost converter encompassing PI controller with closed loop structure has been analyzed to obtain desired fixed output signal through regulation of gain parameters of PI controller. The PI controller parameters are varied taking the natural frequency $\omega_{n}$ and damping factor, $\zeta$ of the system in account. The simulation results show that PI controller parameters tuned with $\omega_{n}$ and zeta, remove the load disturbances along with smooth and precise operation. Besides, variation of these parameters also secures constant output voltages within it's regulated range.

TABLE II. VARIATION OF OVERSHOOT, PEAK TIME AND SETTLING TIME DUE TO THE VARIATION OF DAMPING FACTOR

\begin{tabular}{|c|c|c|c|c|c|}
\hline \multirow[b]{2}{*}{$\zeta$} & \multirow[b]{2}{*}{$K_{P}$} & \multirow[b]{2}{*}{$K_{I}$} & \multicolumn{3}{|c|}{$\operatorname{Voltage}\left(V_{\text {out }}\right)$} \\
\hline & & & $M_{P}(\mathbf{V})$ & $\begin{array}{l}T_{P} \\
(\mathbf{s})\end{array}$ & $\begin{array}{l}T_{S} \\
(\mathbf{s})\end{array}$ \\
\hline $\begin{array}{c}0.1 \\
\text { (Fig. 15) }\end{array}$ & 0.0001 & 0.006 & 0.728 & 0.3949 & 3.75 \\
\hline $\begin{array}{c}0.2 \\
\text { (Fig. 16) }\end{array}$ & 0.0002 & 0.006 & 0.523 & 0.4010 & 1.875 \\
\hline $\begin{array}{c}0.3 \\
\text { (Fig. 17) }\end{array}$ & 0.0004 & 0.006 & 0.372 & 0.4115 & 1.25 \\
\hline $\begin{array}{c}0.4 \\
\text { (Fig. 18) }\end{array}$ & 0.0005 & 0.006 & 0.253 & 0.4282 & 0.9375 \\
\hline $\begin{array}{c}0.5 \\
\text { (Fig. 19) } \\
\end{array}$ & 0.0007 & 0.006 & 0.161 & 0.4532 & 0.75 \\
\hline $\begin{array}{c}0.6 \\
\text { (Fig. 20) }\end{array}$ & 0.0008 & 0.006 & 0.094 & 0.4906 & 0.625 \\
\hline
\end{tabular}

Different parasitic parameters in boost converter cause nonlinearity problem which again incites instability in the system. This research work has also made analysis on subsiding this non-linear phenomenon and the simulation results and the calculation put enough evidence that through concrete codification it is possible to get almost constant output signal from the proposed model which also has less overshoots. Further more, precise regulation may result into fully overdamped response which has been shown in calculation.

DC-DC converters play an imperative role where transient response and fixed output signal are the focusing facts in the field of power electronics. The constant voltage is essential for the grid-connected inverter or micro-inverter system. The gridconnected AC module can be an alternative solution for photovoltaic generation systems. It also requires a high step-up converter and a micro-inverter which remains connected to the grid. This feature of constant output voltage improves the energy-conversion efficiency and this application can be used 
in various sectors such as automotive, power amplifier, adaptive control, battery power system, consumer electronics, communications and so on.

Taking the above facts into consideration, employing MATLAB/Simpower environment the performance of the proposed model, that is, Boost converter incorporating PI controller with closed loop feature has been verified. All the simulation results show commendable performance of the model and also draws the conclusion that the proposed system can be utilized with high stability and efficiency to attain desired fixed signal.

\section{REFERENCES}

[1] Muhammad H. Rashid, "Power Electronics, circuits, devices and applications", Fourth Edition, Pearson, 2014.

[2] Sugandhra Pal Singh, Deepak Kumar Singh, Harish Kumar, Rheesabh Dwivedi, "Designing and parametric variation of PI controller for Buck converter for constant voltage applications", International Journal of Engineering Trends \& Technology, Vol. 13, No. 4, July 2014, pp.169174.

[3] Mitulkumar R. Dave, K.C.Dave, "Analysis of boost converter using PI controller algorithms", International Journal of Engineering Trends \& Technology, Vol. 3, Issue 2, 2012, pp.71-73.

[4] Abhinav Dogra, Kanchan Pal, Solan, "Design of buck-boost converter for constant voltage applications and it's transient response due to parametric variation of PI controller", International Journal of Innovative Research in Science, Engineering \& Technology,Vol.3, Issue 6, June 2014, pp.13579-13587.

[5] Rheesabh Dwivedi, Vinay Kumar Dwivedi, Rahul Sharma,"Parametric variation analysis of CUK converter for constant voltage applications", International Journal of Advanced Research in Electrical, Electronics and Instrumentation Engineering, Vol. 3, Issue 2, February 2014, pp.7108-7117.

[6] Benlafkih Abdessamad, Krit Salah-ddine, Chafik Elidrissi Mohamed, "Design and modelling of DC/DC Boost converter for mobile device applications", International Journal of Science and Technology, Vol. 2, No. 5, May 2013, pp. 394-401.

[7] Norman S. Nise, "Control Systems Engineering," Sixth Edition, John Willey \& Sons, Inc., 2011.

[8] R. Chandrasekaran, K. Suganya, M. Selvamani Prabaharan, "Analysis of PID controller with auto tuning in digitally controlled boost converter", International Journal of Advanced Research Trends in Engineering and Technology, Vol. 2, Issue 5, May 2015, pp. 80-84.

[9] Shetu Roy, and Mohammad Abdul Mannan, "Design of a Closed Loop Boost Converter with Parametric Variation Analysis of PI Controller for Constant Output Voltage Applications" Journal of Power Electronics and Power Systems (JoPEPS)" e(ISSN): 2249-863X, p(ISSN): 23214244 (accepted to published), 2016.

[10] Yachana Chandrakar, "Comparison of open loop and closed loop models for dual input DC-DC Boost converter", International Journal of Emerging Technology and Advanced Engineering, Vol. 3, Issue 6, June 2013, pp.307-311.

[11] Kavita Nanshikar, Aditi Desai, "Simulation of P \& O algorithm using boost converter", International Journal of Innovative Research in
Electrical, Electronics, Instrumentation and Control Engineering, Vol. 4, Issue 2, April 2016, pp.130-135.

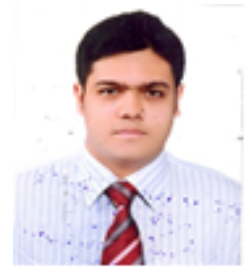

Shetu Roy was born in Comilla, Bangladesh on October 21, 1992. He received his B.Sc. Engg. Degree in EEE from Ahsanullah University of Science and Technology (AUST), Bangladesh in 2014. At present, he is a Masters of Engineering student at EEE Department of American International University-Bangladesh(AIUB).

His research interests are in the field of Power Electronics, Renewable Energy, Power System etc.

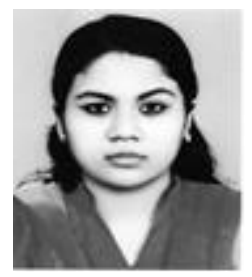

Sumaiya Umme Hani was born in Chittagong, Bangladesh on 31st of July, 1991. She received her B.Sc degree in Electrical and Electronic Engineering from American International University-Bangladesh (AIUB) in May, 2013 and accomplished her Masters program (Master of Science in Electrical and Electronic Engineering) in 2014 from the same institution.

Currently she is working as a Lecturer in at American International University-Bangladesh (AIUB) under the department of EEE. Her research interest includes electric motor drive, power system analysis, power electronics and renewable energy.

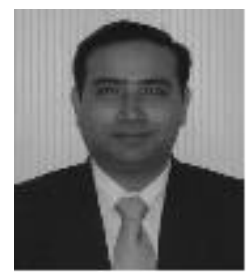

Mohammad Abdul Mannan was born in Laxmipur, Bangladesh on January 01, 1975. He received his B. Sc. Eng. Degree from Rajshahi University of Engineering and Technology (RUET former BITR), Bangladesh, in 1998, and Masters of Eng. and Dr. of Eng. degrees from KItami Institute of Technology, Japan, in 2003 and 2006 respectively, all in electrical engineering. He then joined in the American

International University Bangladesh (AIUB) as an Assistant professor. $\mathrm{He}$ is a member of the IEEE. His research interests include electric motor drive, power electronics, power system, wind generation system and control of electric motor, power electronic converters, power system, and wind generation system. 
